\title{
Comment: "Mapping the scientific research on the negative aspects of the medical school learning environment"
}

Sandra Helena Cerrato Tibiriçá1

1. Head of the Medical Clinic Department, coordinator of the Support Center for Educational Practices NAPE, medical Faculty Federal University of Juiz de Fora, Juiz de Fora, MG, Brasil

The term learning environment encompasses a set of physical, social, and psychological contexts in which a student learns ${ }^{1}$. This is a broad concept that includes the teaching and learning processes, as well as resources and technology, teaching strategies, and connections to society and the global scenario. Medical educators have the responsibility of continuously reassessing their curriculum and the learning environment, rethinking the roles of teachers and students in the construction of a healthy and appropriate learning environment. Most educators agree that the main goals of the education process are to promote students' wellbeing and a healthier environment for the society in which they live. Nevertheless, how should we achieve these goals without a secure and comfortable learning environment?

The study published by Damiano et al. ${ }^{2}$ in this edition of RAMB is an attempt to answer this question. Brazilian medical education is facing a serious moment right now, with several reports of suicide attempts and mental health problems in medical students. Some learning environment aspects could be responsible for these outcomes such as the work overload, little time to extra-curricular activities, teacher-centered activities, limited social and psychological support, unethical faculty behaviors, hidden curriculum, and discriminations ${ }^{3}$. Thus, revisiting the scientific articles on the negative aspects of the learning environment at medical schools around the world is a meaningful way to understand which evidence we have now and what should we do to advance this field of research.

In the comprehensive bibliometric analysis proposed by Damiano et al. ${ }^{2}$, authors identified the most important areas in this field, the type of articles, the trends of publications and the most prolific authors and countries. It is quite clear in their results that the interest in this issue is growing in the last decades, although more experimental, longitudinal, and cross-cultural study designs are needed. Knowing and understanding the positive and also the harmful practices in medical education can foster a broader discussion in this field of research and empower educators to make appropriate changes in their learning environments in order to achieve a desired inclusive education. In my opinion, this article could serve as excellent reading for those interested in education and in the formation of medical and healthcare students. It also arrives in a very good moment for the Brazilian scenario.

\section{REFERENCES}

1. Dunham L, Dekhtyar M, Gruener G, CichoskiKelly E, Deitz |, Elliott D, Stuber ML, Skochelak SE. Medical Student Perceptions of the Learning Environment in Medical School Change as Students Transition to Clinical Training in Undergraduate Medical School. Teach Learn Med. 2017 OctDec;29(4):383-391

2. Damiano RF, Cruz AO, Oliveira JG, DiLalla LF, Tackett S, Ezequiel OS, Lucchetti G. Mapping the scientific research on the Negative Aspects of the Medical School Learning Environment. Rev Assoc Med Bras 2019, 65 (2) 232-239)

3. Shochet RB, Colbert-Getz JM, Wright SM. The Johns Hopkins learning environment scale: measuring medical students' perceptions of the processes supporting professional formation. Acad Med. 2015 Jun;90(6):810-8 